\title{
Ontogenetic disparity in early planktic foraminifers
}

\author{
Sophie Kendall $^{1}$, Felix Gradstein ${ }^{2}$, Christopher Jones $^{3}$, Oliver T. Lord ${ }^{1}$, and Daniela N. Schmidt ${ }^{1}$ \\ ${ }^{1}$ School of Earth Sciences, University of Bristol, Bristol, BS8 1RJ, UK \\ ${ }^{2}$ Natural History Museum, University of Oslo, 0318 Oslo, Norway \\ ${ }^{3}$ School of Physics, University of Bristol, Bristol, BS8 1RJ, UK \\ Correspondence: Daniela N. Schmidt (d.schmidt@bristol.ac.uk)
}

Received: 29 July 2019 - Revised: 28 November 2019 - Accepted: 7 January 2020 - Published: 12 February 2020

\begin{abstract}
Changes in morphology during ontogeny can have profound impacts on the physiology and biology of a species. Studies of ontogenetic disparity through time are rare because of the lack of preservation of developmental stages in the fossil record. As they grow by incremental chamber accretion and retain evidence of growth in their shell, planktic foraminifera are an ideal group for the study ontogenetic disparity through the evolution of a higher taxon. Here, we quantify different developmental stages in Jurassic foraminifers and infer the evolutionary implications of the shape of these earliest representatives of the group. Using a Zeiss Xradia micro-CT scanner, the development of Globuligerina bathoniana and Globuligerina oxfordiana from the Bathonian sediments of Gnaszyn, Poland, and Globuligerina balakhmatovae and Globuligerina tojeiraensis from the Kimmeridgian Tojeira Formation of Portugal was reconstructed. Disparity is low through the early evolution of planktic foraminifers. The number of chambers and range in surface area per unit volume are lower than in modern specimens. We interpret this morphology as an indication of opportunistic behaviour. The low morphological plasticity during the juvenile stage suggests that strong constraints on the juveniles, described in the modern ocean, were already acting on Jurassic specimens. The high surface area per unit volume in these developmental stages points towards the need to satisfy a higher metabolic demand than in the adult specimens. We are interpreting the lower chamber numbers as indicative of short life cycles and potentially rapid reproduction, both of which may have allowed these species to exploit the nutrient-rich waters of the Jurassic Tethys Ocean.
\end{abstract}

1

\section{Introduction}

Disparity refers to the morphological variability within a taxon. Studies of disparity commonly quantify morphospace within and between taxa using adult specimens (e.g. Foote, 1993; Ciampaglio et al., 2001). This focus on adult specimens creates a sample bias that limits the efficacy of the approach by excluding developmental disparity. Fewer studies consider the influence on disparity of ontogenetic change both within taxa and over time (McNamara, 1986; Foote, 1993; McNamara and McKinney, 2005; Gerber et al., 2008) often limited by the lack of complete developmental sequences to perform the analysis.

Planktic foraminiferal morphology has been studied for decades to assess changes in their diversity through time (Ezard, 2011) with applications in biostratigraphy to environmental reconstructions (Perch-Nielsen et al., 1985; Kucera,
2007). All planktic foraminifers possess a calcareous, chambered test (Gradstein et al., 2017a) composed of aragonite or calcite (BouDagher-Fadel et al., 1997). Growth occurs through the addition of chambers (Brummer et al., 1987; Caromel et al., 2016), which are preserved in the adult test, enabling analysis of developmental disparity in a similar way to larger invertebrates such as ammonoids (Bucher et al., 1996). Ontogenetic stages from juvenile to neanic to adult are categorized through changes in morphology (Brummer et al., 1987; Caromel et al., 2016). The adult stage is defined by the maturation of the wall texture and a decline in growth rate. Neanic and juvenile stages are more difficult to differentiate due to the poor preservation of earlier chambers. Several theoretically possible morphologies (Berger, 1969; Tyszka, 2006) are not expressed in their adult morphology.

While modern foraminiferal disparity has been studied recently (Brummer et al., 1987; Caromel et al., 2016; Schmidt 


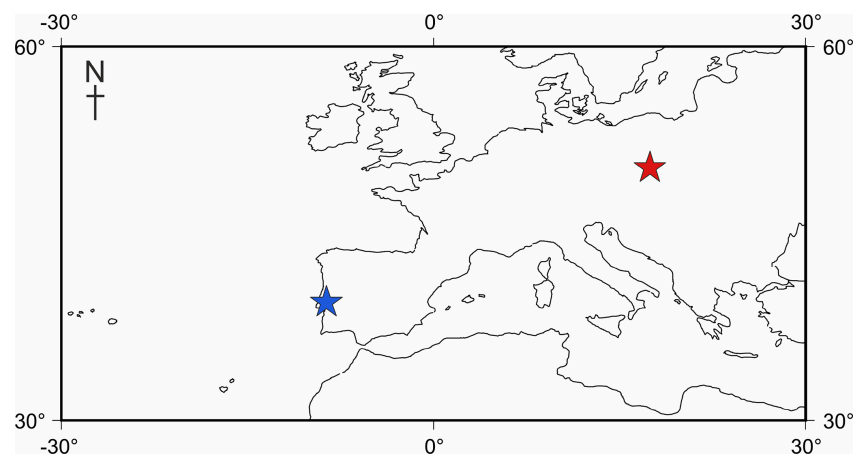

Figure 1. Locality map of Jurassic specimens. The Tojeira Formation is indicated in blue, and Gnaszyn quarry in red. Further locality information provided in Gradstein et al. (2017a). Map taken from http://www.odsn.de, last access: 20 July 2019.

et al., 2016), few studies assess ontogeny in Mesozoic planktic foraminifers (Huber, 1994). Foraminifers are morphologically conservative (Brummer et al., 1986), repeating their same bauplan over and over again after every extinction (Cifelli, 1969). What is unclear is the amount of change in developmental disparity hidden in this conservative morphology. Planktic foraminifers evolved from a benthic ancestor in the Jurassic (Toarcian) Tethys Ocean (BouDagher-Fadel et al., 1997; Gradstein, 2017). Much of the first 40 million years of their evolution is fragmentary due to their small size and aragonitic shells (Gradstein et al., 2017a). The timing and cause of the change in mineralogy from aragonite to calcite is unknown, although it is believed to be post-Jurassic (Gradstein et al., 2017a).

Descriptions have historically relied on poor-quality preservations and acid treatment, which removes many of the taxonomically important features (Gradstein et al., 2017a). Studies of planktic foraminifera development to date have used a variety of tools, the easiest and most accessible being light microscopy and scanning electron microscopy (SEM) (Brummer et al., 1987). These techniques can be informative for descriptive characteristics such as overall morphology (in light microscopy) and wall structure (in SEM) but are less useful for studying ontogenetic changes. No studies of the disparity within the earliest members of the group exist due to their very small size (generally less than $250 \mu \mathrm{m}$ in diameter for the adult specimen) for which the classical approaches of dissecting individual chambers for analysis are ineffective (e.g. Huber, 1994).

Here we analyse the ontogenetic growth patterns of four species of foraminifers using the recently developed technique of micro-CT scanning to reconstruct the developmental history of Jurassic planktic foraminifers and assess if their growth patterns through their development differ from modern foraminifers.

\section{Methods}

\subsection{Specimen specifics}

Four adult specimens from the Jurassic have been selected (Fig. 1) so that complete reconstructions of their ontogeny could be made. Previous work has shown that the developmental trajectories are conservative and highly reducible between specimens of the same species (Caromel et al., 2016). The oldest specimens, Globuligerina bathoniana (Pazdrowa, 1969) and Globuligerina oxfordiana (Grigelis, 1958), are Bathonian (168-166 Ma) in age and from Gnaszyn quarry,

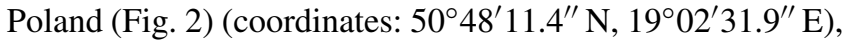
located in the south-west Czesstochowa city area of the Gnaszyn district. The $25 \mathrm{~m}$ thick dark shale represents the part of the Częstochowa ore-bearing clay formation with strongly bioturbated black or dark greyish siltstones and claystones rich in bioclasts. The Jurassic planktonic foraminifera were sampled from the lower part of the section (Morrisi Ammonite Zone-Middle Bathonian), $20 \mathrm{~cm}$ above the $\mathrm{O}$ sphaerosiderite horizon (Gradstein et al., 2017a). The sample contained well-preserved G. oxfordiana and less well-preserved G. bathoniana. The specimens are relatively small and show good detail of wall texture (Gradstein et al., 2017a). These two specimens were chosen as comparative examples of "low-spired" and "high-spired" planktic foraminifera.

Two species from the Kimmeridgian were also selected, Globuligerina balakhmatovae (Morozova and Moskalenko, 1961) and Globuligerina tojeiraensis (Gradstein, 2017); both specimens are from the Tojeira Formation, Portugal (Fig. 2). The Tojeira Formation (Planula-Platynota zones) is over $70 \mathrm{~m}$ of dark grey shales. Pyritized ammonites are common in the lower part of the unit, and silt content increases near the top. Both species are from the same low-spired lineage as G. oxfordiana. Morphological transitions occur between the two species, with $G$. tojeiraensis having a slightly more open umbilicus; the last whorl is less petaloid and chambers more spherical globular and stretched out than in G. balakmatovae sensu stricto (Gradstein et al., 2017a). Samples were washed and picked from the $65-125$ and $125-180 \mu \mathrm{m}$ fractions.

\section{$2.2 \mu \mathrm{CT}$ scanning and metrology}

Using a Zeiss Xradia 520 Versa $\mu$ CT scanner, multiple X-ray projections (radiographs) were acquired through a $360^{\circ}$ rotation of the sample (Görög et al., 2012; Table 1). From these data a 3-D volume was built, allowing for high-quality internal and external analysis (Briguglio et al., 2016). Specimens were mounted onto wooden toothpicks. G. balakhmatovae and G. tojeiraensis appeared to be remarkably clean, but both specimens turned out to be completely infilled, preventing chamber differentiation. The G. bathoniana and G. oxfordiana specimens showed some internal dissolution. Scan specifications (Table 1) were tailored according to the sam- 




Figure 2. 2-D scans and 3-D isosurface reconstructions of Jurassic specimens from Avizo 8.0 (spiral, umbilical, side view). (a-d) Globu-

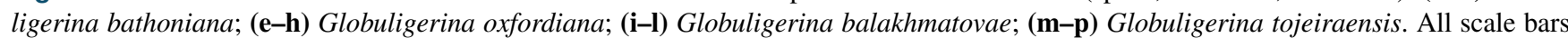
$20 \mu \mathrm{m}$. 
ple attenuation, complexity, size, and time constraints. Data analysis was performed using Avizo 8.0 on raw data in tagsoft data file format (.txm).

Individual slices (tomographs) were viewed by selecting orthoslices in different planar views. A 3-D model was rendered with the isosurface function. Height, length, and width, as well as the spire height and opening rate, were measured and then used to calculate the height / length (HL) and surface area / volume (SAV) ratios for each chamber. As most of the chambers were visible externally on the specimens, estimated chamber sizes could be made despite the poor preservation of the internal chambers in G. balakhmatovae and $G$. tojeiraensis. Division of the chambers in G. bathoniana and G. oxfordiana was done by manually segmenting each chamber because much of the material exhibits similar X-ray attenuation characteristics and is therefore difficult to automatically segment in the 3-D model. From this segmentation, the surface area and volume of each chamber was determined using the "material statistics" module within Avizo 8.0.

\subsection{Mineralogy}

G. bathoniana, G. balakhmatovae, and G. tojeiraensis were analysed using a Thermo Scientific DXRxi confocal Raman imaging microscope with a $455 \mathrm{~nm}$ laser source to identify the carbonate polymorph (calcite or aragonite) from which each foraminifer is made. All analyses used a $100 \times$ long working distance objective lens and a $50 \mu \mathrm{m}$ confocal pinhole. Instrument parameters were chosen in order to maximize the signal-to-noise ratio while preventing beam damage to the samples. Laser power ranged between 1.4 and $4.6 \mathrm{~mW}$, with acquisition times between 0.0625 and $0.1667 \mathrm{~s}$. The spectra reported here are averages between 10 and 100 acquisitions.

\subsection{Wall texture}

Scanning electron microscopy was used to study the differences in wall texture between $G$. bathoniana and $G$. balakhmatovae. Both specimens were broken using a needle, coated with a $10 \mathrm{~nm}$ layer of gold, and analysed using a Hitachi S-3500N SEM with electron beam conditions of $30 \mathrm{nA}$ and $15 \mathrm{kV}$.

\section{Results}

\subsection{Mineralogy}

As expected, the G. bathoniana test is composed of aragonite (Fig. 3a). This interpretation is based on the presence of a mode at $203 \mathrm{~cm}^{-1}$ that is active in aragonite but not calcite. In addition, while the modes at 707 and $1085 \mathrm{~cm}^{-1}$ are shared by both polymorphs, their frequencies are closer to the values expected for biogenic aragonite $(\sim 706$ and $\left.1085 \mathrm{~cm}^{-1}\right)$ than biogenic calcite $\left(\sim 715\right.$ and $1088 \mathrm{~cm}^{-1}$;
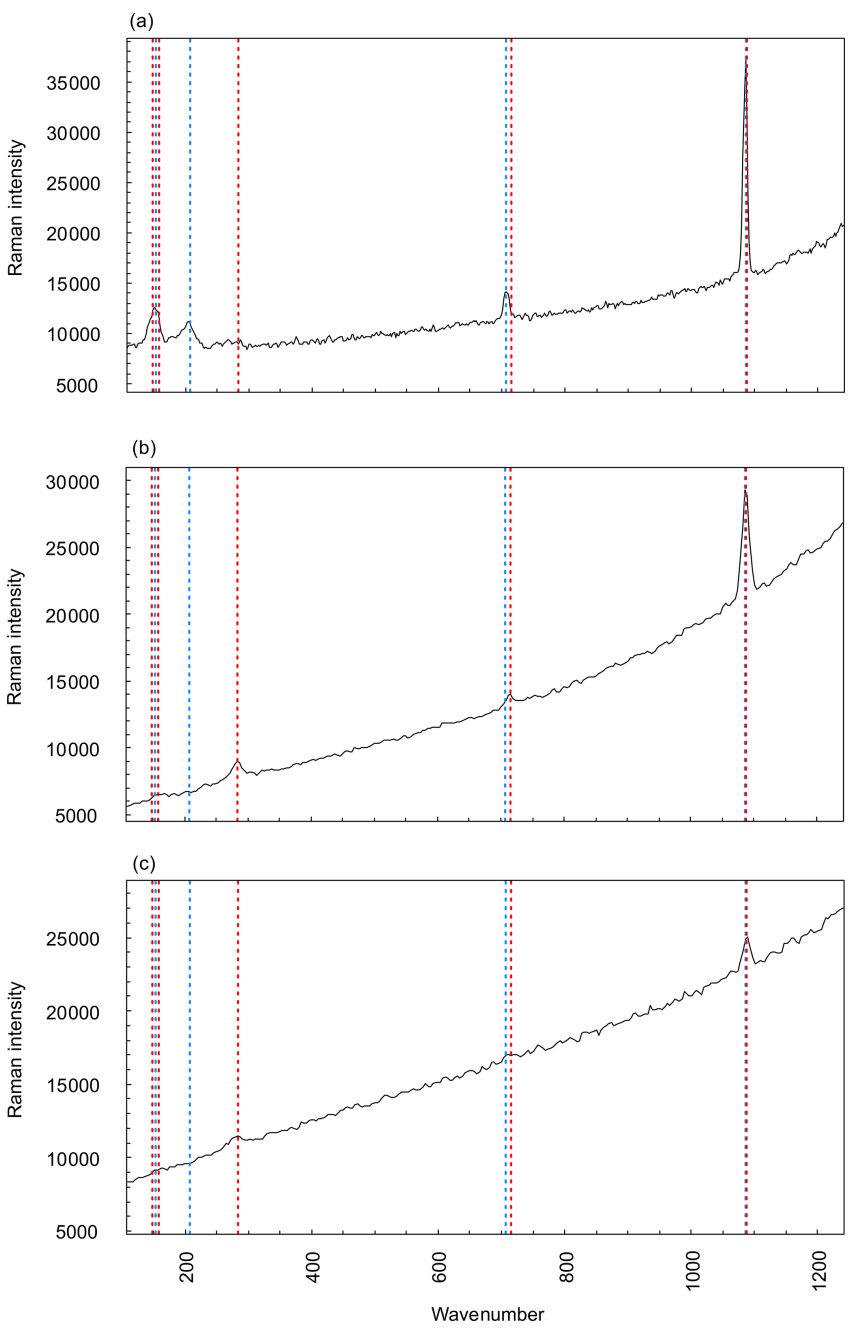

Figure 3. Raman spectroscopy graphs comparing three measured specimens, G. bathoniana (a), G. balakhmatovae (b), and G. tojeiraensis (c), against pre-collected data for aragonite (red dashed) and calcite (blue dashed). Peaks with vertical lines show direct comparisons to calculate the more applicable mineralogy, as denoted by the similarity between peaks and reference modes. Aragonite and calcite present very similar Raman graphs, with the primary difference being the peaks at lower wavenumbers. Higher wavenumbers are differentiated by more precise detail. Reference mode data for aragonite and calcite taken from Urmos et al. (1991).

Urmos et al., 1991). In contrast, our specimens of G. balakhmatovae and G. tojeiraensis are composed of calcite. This interpretation is based on the presence, in both species, of a mode at $283 \mathrm{~cm}^{-1}$ that is present in calcite but not in aragonite. A mode at $1087 \mathrm{~cm}^{-1}$ in both species and a mode at $714 \mathrm{~cm}^{-1}$ that is only present in G. balakhmatovae are also indicative of biogenic calcite (Urmos et al., 1991). 
Table 1. CT-scan specifications used by specimen. Multiple scans were taken with Xradia as high-quality scans take a long time, so preliminary scans were done first.

\begin{tabular}{lrrrrrrrr}
\hline Specimen & $\begin{array}{r}\text { Voltage } \\
(\mathrm{kV})\end{array}$ & $\begin{array}{r}\text { Power } \\
(\mathrm{W})\end{array}$ & Objective & $\begin{array}{r}\text { Time } \\
(\mathrm{h})\end{array}$ & Projections & $\begin{array}{l}\text { Source } \\
\text { filter }\end{array}$ & $\begin{array}{r}\text { Exposure } \\
(\mathrm{s})\end{array}$ & $\begin{array}{r}\text { Camera } \\
\text { binning }\end{array}$ \\
\hline G. bathoniana & 40 & 3 & $40 \times$ & 22 & 3201 & Air & 25 & 2 \\
G. oxfordiana & 60 & 5 & $40 \times$ & 10.5 & 2001 & Air & 18 & 1 \\
G. balakhmatovae & 80 & 7 & $40 \times$ & 14 & 801 & Air & 60 & 1 \\
G. tojeiraensis & 80 & 7 & $40 \times$ & 7 & 801 & Air & 30 & 1 \\
\hline
\end{tabular}

\subsection{Specimen descriptions}

\subsubsection{Globuligerina bathoniana}

The G. bathoniana (Fig. 4) test is a medium trochospire composed of two sinistrally coiling whorls with a maximum length of $127 \mu \mathrm{m}$ by $104 \mu \mathrm{m}$ wide. The specimen is convex on the spiral side. Chambers are not fully spherical, with HL ratios between 0.79 and 1.52 . Sutures between chambers are wide but not pronounced. The aperture is $32 \mu \mathrm{m}$ in diameter and has a defined lip. G. bathoniana is pustulose, particularly in the chambers in the outer whorl (Fig. 5).

Multiple holes can be seen in the outer chambers of the specimen, the largest of which is located on the spiral side and is $16 \mu \mathrm{m}$ in diameter. The holes likely result from dissolution. The earliest chamber (the proloculus) measures $25 \mu \mathrm{m}$ in maximum diameter. Size increases (Fig. 6) isometrically with growth through the juvenile stage. The deuteroconch (second chamber) has a smaller length although the height of the chamber is substantially greater $(22 \mu \mathrm{m}$ as opposed to $33 \mu \mathrm{m})$. Chambers 1 through 5 grow planispirally; the trochospire formed in the outer whorl in chambers 6-10.

\subsubsection{Globuligerina oxfordiana}

The maximum length of G. oxfordiana (Fig. 7) is $126 \mu \mathrm{m}$ by $108 \mu \mathrm{m}$. There is a low trochospiral arrangement over 2.5 dextrally coiling whorls. The spiral side is slightly convex. Chambers are uniform in arrangement. Not all chambers are spherical, with HL ratios between 0.62 and 1.02. Sutures are deep and angles between chambers in the outer whorl are shallow. The aperture is $30 \mu \mathrm{m}$ in diameter; the apertural lip is less pronounced than in G. bathoniana. The final chamber is smooth and shows very few pustules, which are distributed on the preceding chambers.

The proloculus is small in G. oxfordiana at $15 \mu \mathrm{m}$ in diameter. The deuteroconch truncates to $12 \mu \mathrm{m}$, similar to modern species, before showing a steady increase in size. Shape changes at chamber 4 (Table 2) mark the beginning of the neanic stage and gradually becoming more spherical. Growth through the neanic stage begins slowly, increasing at chamber 6 (Fig. 6). A rapid increase in growth rate at chamber 7 is used to define the beginning of the adult stage. Growth tapers off in the last two chambers, and chamber shape reverts to a low HL ratio. The wall texture changes from chamber 9 to the ultimate chamber, becoming smoother, whereas chambers from the beginning of the neanic stage are more pustulose.

\subsubsection{Globuligerina balakhmatovae}

Comprised of 10 sinistrally coiled chambers over two whorls, G. balakhmatovae is comparably large $(246 \mu \mathrm{m}$ by $226 \mu \mathrm{m})$. The specimen is trochospiral with a low spire height, although the spire opening rate is high at 2.5. The specimen is convex towards the spiral side; sutures are deep. Chambers are ovate; the orientation of chambers changes through coiling (Fig. 6). In the outer whorl there are four evenly spaced chambers, with chambers 8 and 9 angled towards the preceding chambers. Internal preservation is poor, so precise calculations of height and length were challenging to obtain. A growth of an opaque dense material, possibly pyrite, comprises $5 \%$ of the total volume of the specimen, obliterating original features. The surface is coarsely pustulose (Fig. 5) and no obvious aperture can be discerned.

Measurements on this specimen were challenging as only external analysis was possible due to the infilling. Tentatively, the proloculus has a size of $25 \mu \mathrm{m}$ by $26 \mu \mathrm{m}$, and the deuteroconch is smaller than the proloculus $(23 \mu \mathrm{m}$ by $22 \mu \mathrm{m})$. Subsequent chambers are less spherical. There is no evidence to support a separation of the juvenile and neanic phase. The adult stage is marked by a growth rate increase at chamber 6 , wherein growth shows a positive allometric trend. In contrast to the trochospiral adult stage, the juvenile stage is planispiral, and there is a negative allometric pattern of growth in globigerinid species such as $G$. sacculifer and G. trilobus (Caromel et al., 2016).

\subsubsection{Globuligerina tojeiraensis}

G. tojeiraensis consists of two dextrally coiled whorls with a low-medium trochospire. With a length of $205 \mu \mathrm{m}$ by $198 \mu \mathrm{m}$, the overall test is large in comparison to other Jurassic species and spherical. There are 10 chambers discernible, although the poor preservation limits the analysis. Chambers are predominantly rounded, with the most variation occurring in the outer whorl. The coiling axis and final chamber are difficult to distinguish. Growth appears to follow a pat- 

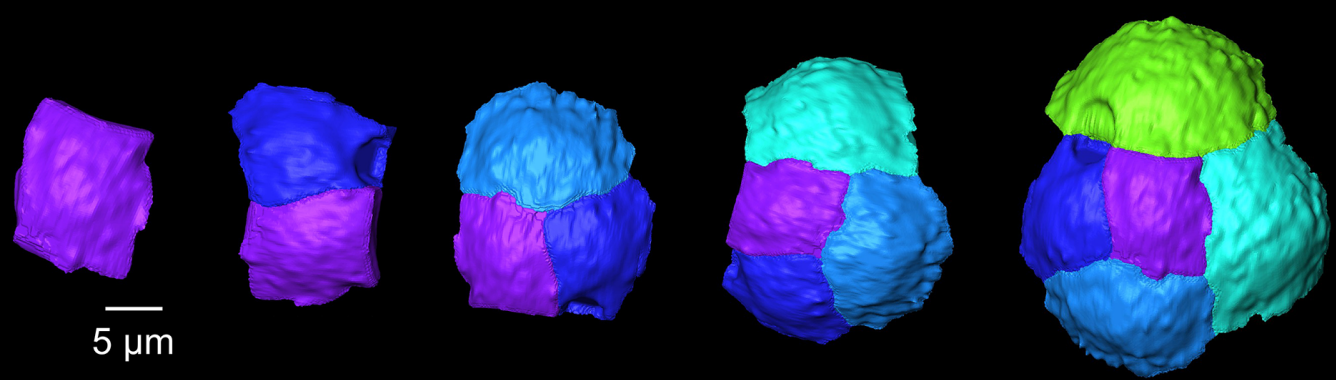

$5 \mu \mathrm{m}$
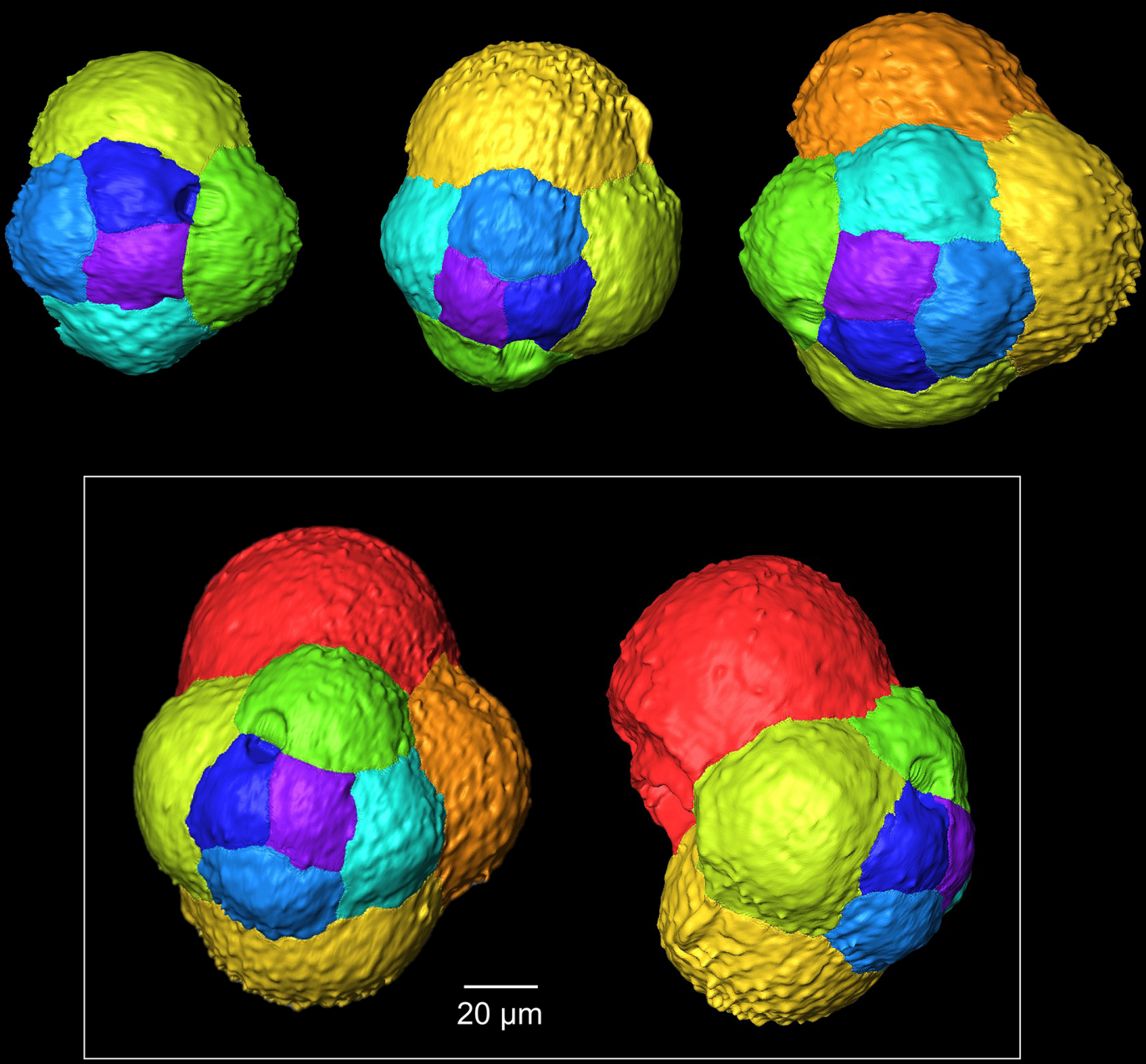

Figure 4. A 3-D reconstruction of $G$. bathoniana with chamber growth beginning from the earliest chamber (proloculus - top left) to the terminal chamber (in the white box). The terminal chamber is presented in spiral and side view, and it is manipulated so that the most recent chamber is at the top. Preservation challenges meant that the earliest chambers were difficult to segment. 

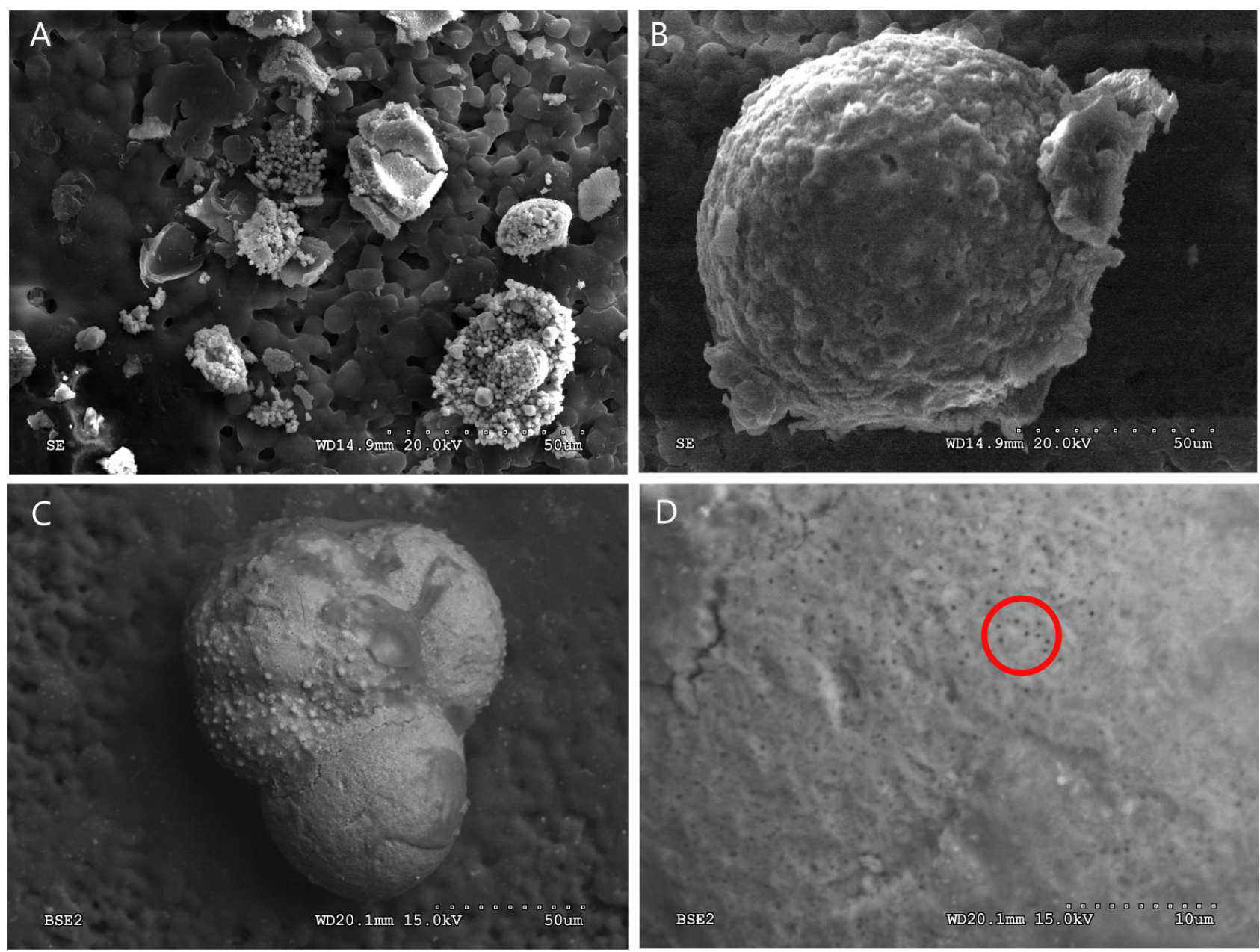

Figure 5. SEM images of G. bathoniana (a) and G. balakhmatovae (b) are gold-coated and broken into fragments to see the internal wall structure. The uncoated $G$. bathoniana shows multiple small pores across the second and third chambers (c, d).

tern in the outer whorl: chambers 7 and 9 are more radially elongate, whereas chambers 8 and 10 are similar in shape. The final chamber is inclined in the direction of coiling. The positioning of chamber 6 compared with chamber 7 is unique compared with the previous specimens; chamber 7 appears to have grown directly behind chamber 6 rather than continuing the previous growth path. Sutures are incised, and the umbilicus is deeply sunken. The aperture could not be determined but is likely to be umbilical (Gradstein et al., 2017a). Wall texture in the latter chambers is coarser. The holes in the walls are post-depositional.

As with $G$. bathoniana, the deuteroconch $(23 \mu \mathrm{m}$ by $29 \mu \mathrm{m})$ is larger than the proloculus $(23 \mu \mathrm{m}$ by $22 \mu \mathrm{m})$. Test growth fluctuates but is generally fast; chamber 5 is smaller than would be expected, creating a dip in growth (Fig. 6). Chamber shape appears to alternate between depressed and radially elongate, varying from an HL value of 0.69 to 1.33. Chambers 1 through 3 decrease in sphericity, becoming more prolate, whereas chambers 4 to 6 are more spherical again, while the shape of the chambers in the final whorl is more varied. Defining the different stages is particularly difficult in this specimen, as the normal descriptive characters that could be used are not observable. G. tojeiraensis does not show clear enough changes in morphology to define a neanic stage. As such only the juvenile and adult stages have been defined. Chambers 1 to 6 represent the juvenile stage, and 7 to 10 the adult stage based on the abrupt change in chamber size and shape (Fig. 6).

\section{Discussion}

In this study, we use the full potential of modern analytical techniques to study the development of early foraminifers. Preservational challenges hindered part of our analysis of the internal structures. Externally, all the specimens are well preserved and chamber texture is easily distinguishable. The poor internal preservation is a result of infilling, reducing the clarity of various features. Dissolution affects all the speci- 

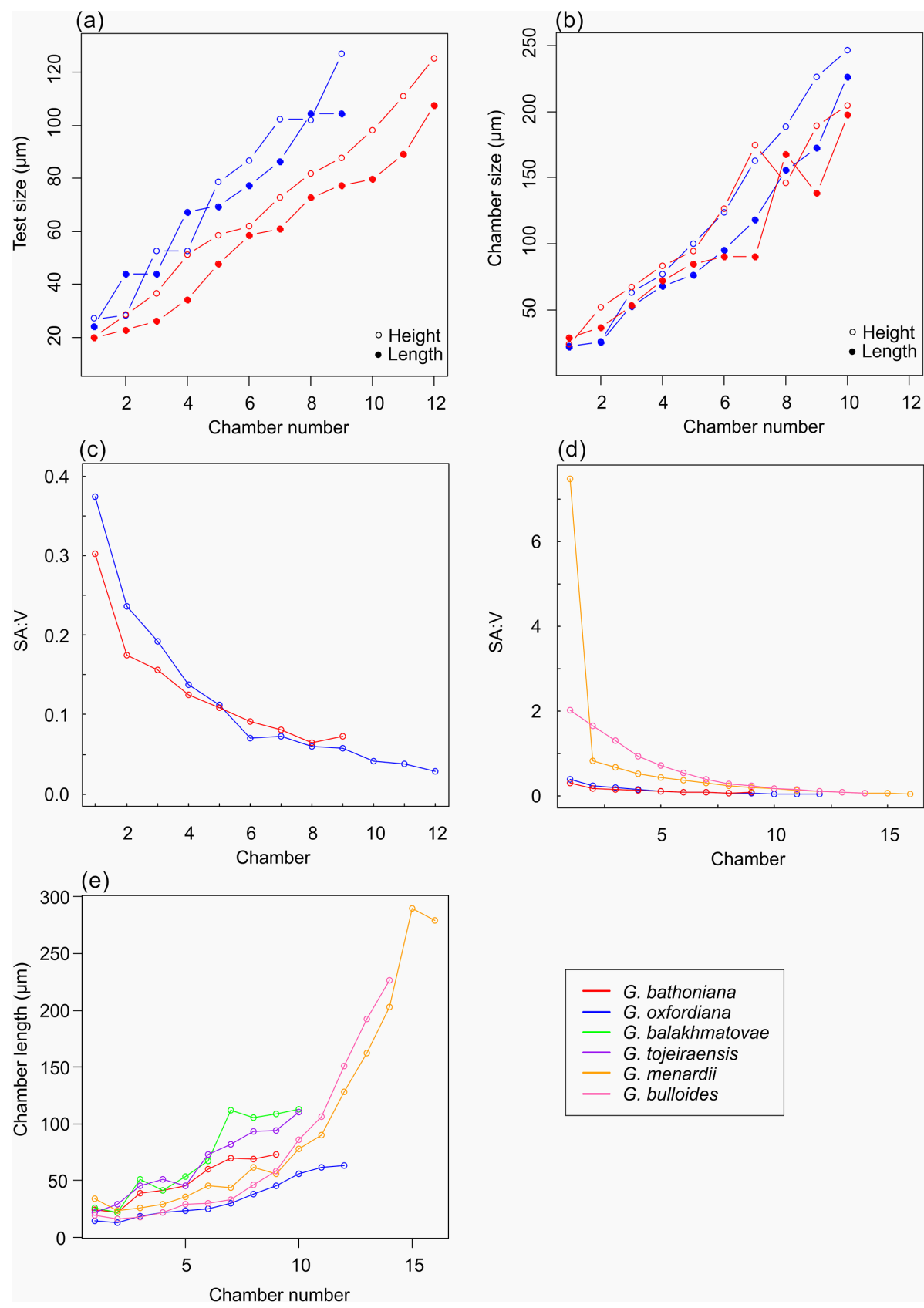

Figure 6. Morphometric growth comparisons between Jurassic species (a-c) and modern species (d-e). Modern specimens represent a globular morphology (G. bulloides) and more complex morphology (G. menardii). Jurassic species indicate more constrained growth trajectories than modern counterparts.

mens (Fig. 1) but is most pronounced in the Kimmeridgian specimens G. balakhmatovae and G. tojeiraensis, likely in response to the large geochemical gradients indicated by the abundant pyrite in the section (see Sect. 2.1). The tests of earliest Jurassic foraminifers have been documented as aragonitic, but the two Kimmeridgian specimens studied here are calcitic. The most plausible explanation for this is that both G. balakhmatovae and G. tojeiraensis have recrystallized from aragonite to calcite. Aragonite is unstable at low pressures (below $\sim 0.4 \mathrm{GPa}$ at $300 \mathrm{~K}$ ) and hence tends to recrystallize when sediments are exhumed (Allison and Bottjer, 2010). This recrystallization (Fig. 5) does not directly affect the evidence of development, but the dissolution within the earliest chambers hinders interpretation. We do not suggest that the "switch" from aragonite to calcite shells occurred prior to the Kimmeridgian.

The overall morphology of the Jurassic specimens is homologous. All specimens have globular chambers, although 


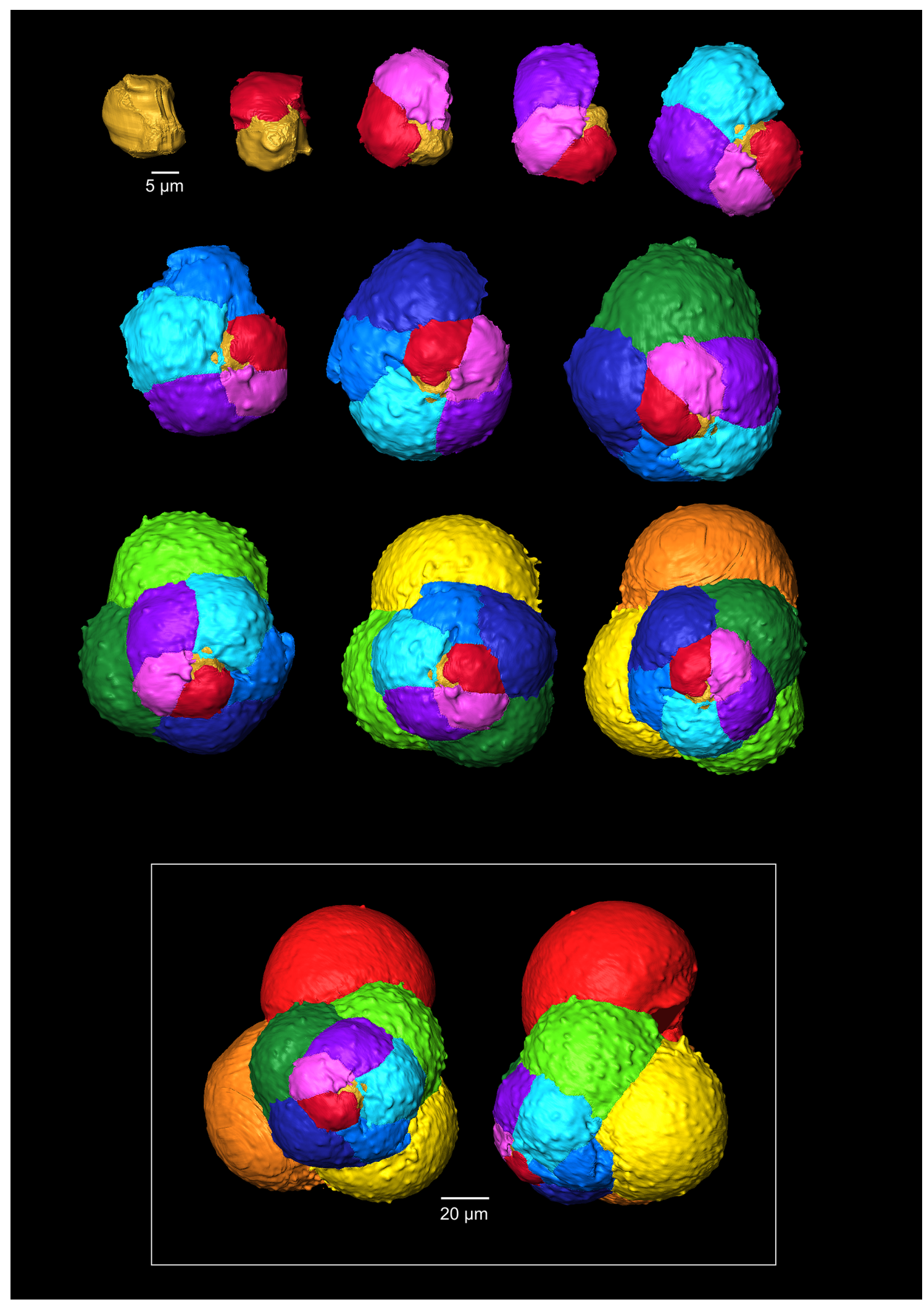

Figure 7. A 3-D reconstruction of G. oxfordiana with chamber growth beginning from the earliest chamber (proloculus - top left) to the terminal chamber (in the white box). The terminal chamber is presented in spiral and side view, and it is manipulated so that the most recent chamber located at the top. 
Table 2. Morphometric comparison of each species. G. balakhmatovae and G. tojeiraensis lack data for volume, surface area, and ratio as these were unable to be obtained.

\begin{tabular}{|c|c|c|c|c|c|c|c|c|c|c|}
\hline Species & $\begin{array}{l}\text { Chamber } \\
\text { number }\end{array}$ & Stage & $\begin{array}{r}L(\mu \mathrm{m}) \\
\text { test }\end{array}$ & $\begin{array}{r}H(\mu \mathrm{m}) \\
\text { test }\end{array}$ & $\begin{array}{r}L(\mu \mathrm{m}) \\
\text { chamber }\end{array}$ & $\begin{array}{c}H(\mu \mathrm{m}) \\
\text { chamber }\end{array}$ & $\begin{array}{r}\text { Vol. }\left(\mu \mathrm{m}^{3}\right) \\
\text { chamber }\end{array}$ & $\begin{array}{l}\text { Vol. }\left(\mu \mathrm{m}^{3}\right) \\
\text { cumulative }\end{array}$ & $\begin{array}{r}\text { SA } \\
\left(\mu \mathrm{m}^{2}\right)\end{array}$ & Ratio \\
\hline G. bathoniana & 1 & Juvenile & 24.26 & 27.12 & 24.26 & 25.12 & 6908 & 6908 & 2087 & 0.30 \\
\hline G. bathoniana & 2 & Juvenile & 44.01 & 28.2 & 21.53 & 32.64 & 8051 & 14959 & 2622 & 0.33 \\
\hline G. bathoniana & 3 & Neanic & 44.07 & 52.62 & 39.33 & 30.94 & 16363 & 24414 & 3806 & 0.23 \\
\hline G. bathoniana & 4 & Neanic & 67.38 & 52.62 & 41.46 & 34.33 & 24460 & 40823 & 5087 & 0.21 \\
\hline G. bathoniana & 5 & Neanic & 69.52 & 78.63 & 45.21 & 39.31 & 42247 & 66707 & 7209 & 0.17 \\
\hline G. bathoniana & 6 & Neanic & 77.45 & 86.86 & 60.48 & 51.5 & 60695 & 102942 & 9361 & 0.15 \\
\hline G. bathoniana & 7 & Adult & 86.25 & 102.44 & 69.56 & 60.74 & 100852 & 161547 & 13141 & 0.13 \\
\hline G. bathoniana & 8 & Adult & 104.51 & 102.17 & 68.94 & 59.95 & 89295 & 190147 & 12194 & 0.14 \\
\hline G. bathoniana & 9 & Adult & 104.66 & 127.04 & 73.15 & 66.92 & 172304 & 261599 & 18980 & 0.11 \\
\hline G. oxfordiana & 1 & Juvenile & 19.90 & 20.04 & 15.00 & 15.25 & 3490 & 3490 & 1306 & 0.37 \\
\hline G. oxfordiana & 2 & Juvenile & 22.72 & 28.66 & 13.02 & 11.54 & 2464 & 5955 & 1403 & 0.24 \\
\hline G. oxfordiana & 3 & Juvenile & 26.16 & 36.77 & 18.54 & 15.04 & 5613 & 11568 & 2220 & 0.19 \\
\hline G. oxfordiana & 4 & Neanic & 34.23 & 51.26 & 22.01 & 13.55 & 10829 & 22397 & 3094 & 0.14 \\
\hline G. oxfordiana & 5 & Neanic & 47.71 & 58.72 & 23.82 & 15.20 & 15782 & 38179 & 4262 & 0.11 \\
\hline G. oxfordiana & 6 & Neanic & 58.52 & 61.91 & 24.98 & 16.68 & 13662 & 51841 & 3658 & 0.07 \\
\hline G. oxfordiana & 7 & Adult & 60.96 & 72.94 & 29.92 & 22.42 & 26330 & 78170 & 5682 & 0.07 \\
\hline G. oxfordiana & 8 & Adult & 72.69 & 81.97 & 38.45 & 28.22 & 38677 & 116847 & 7034 & 0.06 \\
\hline G. oxfordiana & 9 & Adult & 77.40 & 87.76 & 45.45 & 30.34 & 72816 & 189663 & 10952 & 0.06 \\
\hline G. oxfordiana & 10 & Adult & 79.90 & 98.24 & 55.70 & 37.09 & 91216 & 280879 & 11762 & 0.04 \\
\hline G. oxfordiana & 11 & Adult & 89.14 & 111.21 & 61.33 & 48.54 & 147265 & 428144 & 16471 & 0.04 \\
\hline G. oxfordiana & 12 & Adult & 107.51 & 125.54 & 63.20 & 52.52 & 161087 & 589231 & 16533 & 0.03 \\
\hline G. balakhmatovae & 1 & Juvenile & 22.56 & 23.17 & 25.67 & 24.56 & & & & \\
\hline G. balakhmatovae & 2 & Juvenile & 25.86 & 26.29 & 22.09 & 23.01 & & & & \\
\hline G. balakhmatovae & 3 & Juvenile & 53.00 & 63.09 & 51.20 & 38.84 & & & & \\
\hline G. balakhmatovae & 4 & Juvenile & 68.44 & 77.13 & 41.79 & 38.11 & & & & \\
\hline G. balakhmatovae & 5 & Juvenile & 76.71 & 100.54 & 53.55 & 43.72 & & & & \\
\hline G. balakhmatovae & 6 & Adult & 95.47 & 123.94 & 67.26 & 66.81 & & & & \\
\hline G. balakhmatovae & 7 & Adult & 117.98 & 163.05 & 112.38 & 88.97 & & & & \\
\hline G. balakhmatovae & 8 & Adult & 155.82 & 188.66 & 105.41 & 100.06 & & & & \\
\hline G. balakhmatovae & 9 & Adult & 172.28 & 225.87 & 108.47 & 115.02 & & & & \\
\hline G. balakhmatovae & 10 & Adult & 226.48 & 246.31 & 112.91 & 105.38 & & & & \\
\hline G. tojeiraensis & 1 & Juvenile & 29.55 & 24.15 & 22.13 & 23.41 & & & & \\
\hline G. tojeiraensis & 2 & Juvenile & 36.64 & 52.1 & 29.04 & 22.78 & & & & \\
\hline G. tojeiraensis & 3 & Juvenile & 53.52 & 67.45 & 45.23 & 31.21 & & & & \\
\hline G. tojeiraensis & 4 & Juvenile & 72.16 & 83.85 & 51.42 & 46.18 & & & & \\
\hline G. tojeiraensis & 5 & Juvenile & 85.13 & 94.50 & 45.33 & 42.31 & & & & \\
\hline G. tojeiraensis & 6 & Adult & 90.65 & 126.98 & 73.21 & 64.74 & & & & \\
\hline G. tojeiraensis & 7 & Adult & 90.65 & 174.63 & 81.61 & 108.57 & & & & \\
\hline G. tojeiraensis & 8 & Adult & 167.98 & 146.01 & 93.13 & 96.48 & & & & \\
\hline G. tojeiraensis & 9 & Adult & 138.36 & 189.42 & 93.90 & 122.67 & & & & \\
\hline G. tojeiraensis & 10 & Adult & 197.69 & 204.73 & 110.05 & 103.07 & & & & \\
\hline
\end{tabular}

individual chamber shape shows some variations. In general, across the analysed taxa, chamber and test size are similar with a consistent bauplan (preset morphology) due to early ontogenetic constraints. All specimens show an exponential growth pattern comparable to modern specimens (Schmidt et al., 2013).

Ontogenetic stages can be categorized broadly by changes in morphology (Brummer et al., 1987; Caromel et al., 2016).
In modern foraminifers, there is a difference in allometric rates between the two main groups of globigerinid and globorotaliid species. Globigerinids have easily identifiable growth stages based upon changes in growth rate and qualitative characteristics such as maturation of the wall texture. In contrast, the definitions of the growth stages of the globorotaliids rely more upon changes in chamber shape and are thus more difficult to differentiate. Based on growth rates and de- 
velopmental transitions, the Jurassic specimens are morphologically closest to the globigerinid group.

Organisms that grow isometrically are normally small and simplistic in morphology (Stanley, 1973; Gould, 1988). Following this paradigm, the simple chamber arrangements of Jurassic foraminifers should suggest isometric growth. While this is true for the juvenile stage in G. bathoniana and $G$. tojeiraensis, it is not the case in G. oxfordiana or G. balakhmatovae. In these species, shell coiling is planispiral during the juvenile stage. In G. balakhmatovae and G. tojeiraensis, and to a lesser extent in G. bathoniana, growth is not steady throughout development. The early ontogeny of G. tojeiraensis is isometric but by the adult stage is negatively allometric: a feature seen in modern globorotaliid species such as Globorotalia menardii.

Despite the overall differences in growth trajectories, all Jurassic specimens show growth constraints during the juvenile stage. Juvenile chambers in all studied specimens are so spherical, smooth, and uniform that they are indistinguishable. Early ontogenetic constraints are also evident in extant species of both main groups, e.g. G. menardii and G. bulloides, indicating that this constraint has been selected for prior to their last common ancestor. G. oxfordiana, G. balakhmatovae, and G. tojeiraensis transition to adult at approximately half their overall size, similar to the modern species G. bulloides and Globigerinella siphonifera. In contrast, G. bathoniana transitions at $80 \%$ of its final size. We speculate that the growth transition is driven by a similar physiological reason necessitating an optimization of surface to volume ratios.

Changes in the timing of development have been linked with change through evolution (McKinney, 1986), creating variation between specimens. Although taxonomic links for Jurassic specimens are hard to establish, it has been suggested that $G$. tojeiraensis is a descendant of $G$. oxfordiana (Gradstein et al., 2017a). Morphologically, these specimens both show the "standard" simple Jurassic pattern of globular chambers arranged in a low trochospire. However, the developmental path of $G$. tojeiraensis has a greater resemblance to $G$. balakhmatovae than to G. oxfordiana. Both $G$. oxfordiana and $G$. tojeiraensis grow allometrically during the adult stage. Differentiation of the neanic and juvenile stages of both G. tojeiraensis and G. balakhmatovae proved to be challenging due to the poor preservation and the lack of clear differentiation of features, leading us to separate ontogeny into juvenile and adult stages only. Both G. bathoniana and G. oxfordiana show neoteny, or slow development, indicated by the small increase in size and volume with each new chamber added.

The surface area of passive feeding organisms provides insight into metabolic efficiency (Signes et al., 1993), while the volume determines overall metabolic requirements. In planktic foraminifers, volume indicates reproductive success as all the cytoplasm will be converted into gametes in the terminal stage. The constraint on chamber form and growth in the juvenile stage results in higher SAV ratios than in adult foraminifers. During the earlier stages of development specimens have a higher SAV (Fig. 6) optimized for rapid food uptake to sustain a potentially high metabolic activity. Allometric growth through ontogeny results in a decline in SAV and thus metabolic efficiency. In modern species, surface area and volume are related to trophic behaviours: juveniles are herbivorous surface dwellers (Hemleben et al., 1989) but develop to become more specialized (Grigoratou et al., 2019). The benefit of herbivory for early developmental stages was also suggested by a trait modelling approach as it provides small specimens with an optimum size prey which is abundant in all environments (Grigoratou et al., 2019). A low metabolic efficiency is suggested by the decline in the SAV ratio through the adult stage, which in modern species has been related to the change to the carnivorous diet (Hemleben et al., 1989; Caromel et al., 2016). In the same model, adult foraminifera needed to be more generalist, especially in oligotrophic environments, to sustain their energetic needs. This might be specifically true during the Jurassic before the development of large phytoplankton such as diatoms (Kooistra et al., 2007).

Experiments have shown that modern planktic foraminifera exhibit strong morphological plasticity as a result of the environment they inhabit (Hecht, 1976; Hecht et al., 1976; Malmgren and Kennett, 1976; Renaud and Schmidt, 2003). The Jurassic species all possess globular chambers, with some differentiation on the height and length of each chamber. By analogy to modern species and disparity after crisis (Cifelli, 1969), the simple globular chambers suggest that the Jurassic specimens were not specialized. It has been suggested that there is a typical size ratio between predator and prey of 10:1 (Kiørboe, 2008), which might explain the small size of Jurassic foraminifers. The final chamber size of both G. balakhmatovae and G. tojeiraensis suggests a growth plateau which might be interpreted as stunted growth due to the lack of optimal environments.

The adult test size increases between the Bathonian (104 to $127 \mu \mathrm{m})$ and Kimmeridgian (197 to $246 \mu \mathrm{m}$ ). This observation can be interpreted as an increase in size following Cope's rule or sampling species which are well or less well adapted to the habitat in which we sampled them as stressful habitats have been suggested to lead to smaller size (Schmidt et al., 2004, 2006). Hallam (2001) noted that the size of planktic foraminifers increases during transgressive cycles, which occur through the later Jurassic. These time intervals are overall warm climates with increased shelf habitats; these have been suggested to result in higher diversity and high productivity in the photic zone (Röhl et al., 2001; Gradstein et al., 2017b). Compared to modern species, the Jurassic specimens possess fewer chambers, which may indicate a faster reproduction time. The high population size supported by earlier gametogenesis may indicate an opportunistic species. If true, this hypothesis has two consequences: firstly, it suggests that the population size would have been larger, and 
secondly it raises the question of whether these specimens had the strong circadian clock which controls reproduction in modern species (Hemleben et al., 1989). The Polish sections contain ammonites, belemnites, bivalves, scaphopods, gastropods, foraminifers, echinoderms, and shark teeth, as well as trace fossils, calcareous nannoplankton, pollen, sphoromorphs, dinoflagellates, and driftwood (Gradstein et al., 2017a), suggesting a shallow-water habitat. If their habitats had been limited to marine continental margin conditions instead of the distal open ocean (Gradstein et al., 2017b) with high population densities, maybe reproduction could have happened more frequently, supported by the higher nutrient availability in these settings.

\section{Conclusions}

Jurassic foraminiferal disparity is low as all species have globular chambers with minor differences in shape. The small number of chambers compared to modern species is interpreted as resulting from a short life cycle (compared to modern specimens) and might be the result of rapid reproduction in nutrient-rich coastal environments. Therefore, our findings support the idea that these were opportunistic bloom species.

The comparison of the ontogenetic sequence between species suggests that juveniles are constrained throughout their morphological evolution akin to modern species. The high SAV ratios point towards the need to satisfy a higher metabolic demand compared to the adult specimens.

Disparity of adult planktic foraminifers increases throughout their evolution. Despite this increase, extant planktic foraminifers show the same ontogenetic constraints as their earliest ancestors, suggesting that there is a specific bauplan operating on all planktic foraminifers.

Data availability. The data can be downloaded at https://doi.org/10.1594/PANGAEA.908790 (Kendall et al., 2019a); the scan data are stored under https://doi.org/10.5523/bris.11s162bxefmsx2rilr389289cw (Kendall et al., 2019b).

Sample availability. Any sample requests should be addressed to Felix Gradstein.

Author contributions. DNS and FG designed the project, CJ performed the CT analysis, OTL the Raman spectroscopy, and SK all other analysis. SK and DNS wrote the paper, and all other authors contributed to the interpretation.

Competing interests. The authors declare that they have no conflict of interest.
Acknowledgements. Daniela N. Schmidt acknowledges funding from the Royal Society via a Wolfson Merit Award and OTL through a University Research Fellowship (no. UF150057); Sophie Kendall received funding from the University of Bristol Alumni Foundation.

Review statement. This paper was edited by Kirsty Edgar and reviewed by Matías Reolid and one anonymous referee.

\section{References}

Allison, P. A. and Bottjer, D. J.: Taphonomy: Process and Bias Through Time, Springer, New York, 560 pp., 2010.

Berger, W. H.: Planktonic Foraminifera?: Basic Morphology and Ecologic Implications, J. Paleontol., 43, 1369-1383, 1969.

BouDagher-Fadel, M. K., Banner, F. T., and Whittaker, J. E.: Early evolutionary history of planktonic foraminifera, Chapham \& Hall, London, 269 pp., 1997.

Briguglio, A., Kinoshita, S., Hohenegger, J., and Wolfgring, E.: Morphological variations in Cycloclypeus carpenteri: multiple embryos and multiple equatorial layers, Palaeontol. Electron., 19, 1-22, 2016.

Brummer, G. J. A., Hemleben, C., and Spindler, M.: Planktonic foraminiferal ontogeny and new perspectives for micropalaeontology, Nature, 319, 50-52, https://doi.org/10.1038/319050a0, 1986.

Brummer, G. J. A., Hemleben, C., and Spindler, M.: Ontogeny of extant spinose planktonic foraminifera (Globigerinidae): A concept exemplified by Globigerinoides sacculifer (Brady) and G. Ruber (d'Orbigny), Mar. Micropaleontol., 12, 357-381, https://doi.org/10.1016/0377-8398(87)90028-4, 1987.

Bucher, H., Landman, N. H., Klofak, S. M., and Guex, J.: Mode and rate of growth in ammonoids, in: Ammonoid Paleobiology, edited by: Landman, N. H., Plenum Press, New York, 408-461, 1996.

Caromel, A. G. M., Schmidt, D. N., Fletcher, I., and Rayfield, E. J.: Morphological Change During The Ontogeny Of The Planktic Foraminifera, J. Micropalaeontol., 35, 2-19, https://doi.org/10.1144/jmpaleo2014-017, 2016.

Ciampaglio, C. N., Kemp, M., and McShea, D. W.: Paleontological Society Detecting Changes in Morphospace Occupation Patterns in the Fossil Record?: Characterization and Analysis of Measures of Disparity, Paleobiology, 27, 695-715, 2001.

Cifelli, R. L.: Radiation of Cenozoic Planktonic Foraminifera, Syst. Zool., 18, 154-168, https://doi.org/10.2307/2412601, 1969.

Ezard, T. H. G.: Interplay Between Changing Climate and Species' Ecology Drives Macroevolutionary Dynamics, Science, 332, 349-351, https://doi.org/10.1126/science.1203060, 2011.

Foote, M.: Contributions of individual taxa to overall morphological disparity, Paleobiology, 19, 403-419, 1993.

Gerber, S., Eble, G. J., and Neige, P.: Allometric space and allometric disparity: A developmental perspective in the macroevolutionary analysis of morphological disparity, Evolution, 62, 14501457, 2008.

Görög, Á., Szinger, B., Tóth, E., and Viszkok, J.: Methodology of the micro-computer tomography on foraminifera, Palaeontol. Electron., 15, 1-15, 2012. 
Gould, S. J. A. Y.: Trends as Changes in Variance?: A New Slant on Progress and Directionality in Evolution, J. Paleontol., 62, 319329, 1988.

Gradstein, F. M.: The planktonic foraminifera of the Jurassic, Part III: annotated historical review and references, Swiss J. Palaeontol., 136, 273-285, https://doi.org/10.1007/s13358-017-0130-0, 2017.

Gradstein, F., Gale, A., Kopaevich, L., Waskowska, A., Grigelis, A., and Glinskikh, L.: The planktonic foraminifera of the Jurassic, Part I: material and taxonomy, Swiss J. Palaeontol., 136, 187257, 2017a.

Gradstein, F., Gale, A., Kopaevich, L., Waskowska, A., Grigelis, A., Glinskikh, L., and Görög, Á.: The planktonic foraminifera of the Jurassic. Part II: Stratigraphy, palaeoecology and palaeobiogeography, Swiss J. Palaeontol., 136, 259-271, 2017b.

Grigelis, A. A.: Globigerina oxfordiana sp. n. - an occurrence of Globigerina in the Upper Jurassic deposits of Lithuania. Nauchnyye Doklady Vysshey Shkoly, Geol-Geogr Nauki, 1958, 109111,1958

Grigoratou, M., Monteiro, F. M., Schmidt, D. N., Wilson, J. D., Ward, B. A., and Ridgwell, A.: A trait-based modelling approach to planktonic foraminifera ecology, Biogeosciences, 16, 14691492, https://doi.org/10.5194/bg-16-1469-2019, 2019.

Hallam, A.: A review of the broad pattern of Jurassic sea-level changes and their possible causes in the light of current knowledge, Palaeogeogr. Palaeocl, 167, 23-37, 2001.

Hecht, A. D.: An ecologic model for test size variation recent planktonic foraminifera: application to the fossil record, J. Foraminifer. Res., 6, 295-311, 1976.

Hecht, A. D., Bé, A. W., and Lott, L.: Ecologic and paleoclimatic implications of morphologic variation of Orbulina universa in the Indian Ocean, Science, 194, 422-424, 1976.

Hemleben, C., Spindler, M., and Anderson, O. R.: Modern Planktonic Foraminifera, Springer-Verlag, New York, 363 pp., 1989.

Huber, B. T.: Ontogenetic morphometrics of some Late Cretaceous trochospiral planktonic foraminifera from the Austral Realm, Smithson. Contrib. Paleobiol., 85 pp., https://doi.org/10.5479/si.00810266.77.85, 1994.

Kendall, S., Gradstein, F., Jones, C., Lord, O. T., and Schmidt, D. N.: Ontogenetic disparity in early planktic foraminifers, https://doi.org/10.1594/PANGAEA.908790, 2019a.

Kendall, S., Gradstein, F., Jones, C., Lord, O. T., and Schmid, D. N.: Ontogenetic disparity in early planktic foraminifers, https://doi.org/10.5523/bris.11s162bxefmsx2rilr389289cw, 2019 b.

Kiørboe, T.: Zooplankton feeding rates and bioenergetics, in A Mechanistic Approach to Plankton Ecology, Princeton University Press, 101-121, 2008.

Kooistra, W. H. C. F., Gersonde, R., Medlin, L. K., and Mann, D. G.: The Origin and Evolution of the Diatoms, in Evolution of Primary Producers in the Sea, Academic Press, 207-249, 2007.

Kucera, M.: Planktonic Foraminifera as Tracers of Past Oceanic Environments, Dev. Mar. Geol., 1, 213-262, 2007.
Malmgren, B. A. and Kennett, J. P.: Biometric analysis of phenotypic variation in recent Globigerina bulloides d'Orbigny in the Southern Indian Ocean, Mar. Micropaleontol., 1, 3-25, 1976.

McKinney, M. L.: Ecological Causation of Heterochrony?: A Test and Implications for Evolutionary Theory, Paleobiology, 12, 282-289, 1986.

McNamara, K. J.: A Guide to the Nomenclature of Heterochrony, J. Paleontol., 60, 4-13, 1986.

McNamara, K. J. and McKinney, M. L.: Heterochrony, disparity, and macroevolution, Paleobiology, 31, 17-26, 2005.

Morozova, V. G. and Moskalenko, T. A.: Foraminiferes planctoniques des depots limitrophes du Bajocien et du Bathonien du Daghestan central (Nord-Est du Caucase), Voprosy Mikropaleontologii, 5, 3-30, 1961.

Pazdrowa, O.: Bathonian Globigerina of Poland, Rocznik Polskiego Towarzystwa Geologicznego, 39, 41-56, 1969.

Perch-Nielsen, K., Saunders, J. B., and Bolli, H. M.: Plankton stratigraphy, Cambridge University Press, 1032 pp., 1985.

Renaud, S. and Schmidt, D. N.: Habitat tracking as a response of the planktic foraminifer Globorotalia truncatulinoides to environmental fluctuations during the last $140 \mathrm{kyr}$, Mar. Micropaleontol., 49, 97-122, 2003.

Röhl, H.-J., Schmid-Röhl, A., Oschmann, W., Frimmel, A., and Schwark, L.: The Posidonia Shale (Lower Toarcian) of SWGermany: an oxygen-depleted ecosystem controlled by sea level and palaeoclimate, Palaeogeogr. Palaeocl., 165, 27-52, 2001.

Schmidt, D. N., Thierstein, H. R., and Bollmann, J.: The evolutionary history of size variation of planktic foraminiferal assemblages in the Cenozoic, Palaeogeogr. Palaeocl., 212, 159-180, 2004.

Schmidt, D. N., Lazarus, D., Young, J. R., and Kucera, M.: Biogeography and evolution of body size in marine plankton, Earth-Sci. Rev., 78, 239-266, https://doi.org/10.1016/j.earscirev.2006.05.004, 2006.

Schmidt, D. N., Rayfield, E. J., Cocking, A., and Marone, F.: Linking evolution and development: Synchrotron Radiation X-ray tomographic microscopy of planktic foraminifers, Palaeontology, 56, 741-749, 2013.

Schmidt, D. N., Caromel, A. G. M., Seki, O., Rae, J. W. B., and Renaud, S.: Morphological response of planktic foraminifers to habitat modifications associated with the emergence of the Isthmus of Panama, Mar. Micropaleontol., 128, 28-38, 2016.

Signes, M., Bijma, J., Hemleben, C., and Ott, R.: A Model for Planktic Foraminiferal Shell Growth, Paleobiology, 19, 71-91, 1993.

Stanley, S. M.: An explanation for Cope's Rule, Evolution, 27, $1-$ 26, 1973.

Tyszka, J.: Morphospace of foraminiferal shells: Results from the moving reference model, Lethaia, 39, 1-12, https://doi.org/10.1080/00241160600575808, 2006.

Urmos, J., Sharma, S. K., and Mackenzie, F. T.: Characterization of some biogenic carbonates with Raman spectroscopy, Am. Mineral., 76, 641-646, 1991. 